\title{
DIBUJOS DE LA VIRGEN DE LOS REYES CONSERVADOS EN LA COLECCIÓN GESTOSO
}

\author{
"VIRGEN DE LOS REYES" (OUR LADY OF KINGS) \\ DRAWINGS IN THE GESTOSO COLLECTION
}

\author{
Teresa Laguna Paúl \\ Universidad de Sevilla. España \\ teresalaguna@us.es
}

\begin{abstract}
Estudio de los dibujos del movimiento de la cabeza y zapatillas de la Virgen de los Reyes originales de José Gestoso (1890-1893), cabezas de la Virgen y del Niño con sus coronas antiguas de Joaquín Domínguez Bécquer (1817-1879), y boceto de corona neogótica del orfebre José Lecaroz dibujada por José Macías y Macías (1904). La investigación profundiza en el conocimiento de esta escultura del siglo XIII y aporta novedades a la historiografía de José Gestoso.

Palabras clave: Virgen de los Reyes; Catedral de Sevilla; José Gestoso; Joaquín Domínguez Bécquer; José Lecaroz.
\end{abstract}

This paper studies José Gestoso's 1890-93 drawings of the head's movement and the shoes in the statue of the "Virgen de los Reyes" (Our Lady of Kings). It also analyses drawings by Joaquín Domínguez Bécquer of the heads of both Virgin and Child in the same statue, and José Macías y Macías's 1904 sketch of the neo-gothic crown made by goldsmith José Lecaroz. This article updates knowledge on this $13^{\text {th }}$ century statue and offers new insight into José Gestoso's historiography.

Keywords: Our Lady of Kings ("Virgen de los Reyes"); Seville Cathedral; José Gestoso; Joaquín Domínguez Bécquer; José Lecaroz.

\section{INTRODUCCIÓN}

Conocido el interés y dedicación del profesor Juan Miguel González Gómez al estudio de la iconografía mariana, es grato dedicarle y dar a conocer, en este homenaje académico del Departamento de Historia del Arte, unos dibujos de la Virgen de los Reyes conservados en la colección que don José Gestoso y Pérez donó a la 
Biblioteca Capitular y Colombina de la Catedral de Sevilla en 1917. Su existencia la señalé en otros estudios de la primitiva capilla Real pero las informaciones señaladas entonces necesitaban un trabajo monográfico e historiográfico, que aportará luz para conocer las investigaciones de Gestoso sobre la Virgen de los Reyes.

Estos dibujos inéditos revelan aspectos interesantes de sus investigaciones y metodología, de su interés por la salvaguarda patrimonial y la difusión de sus resultados. Sus publicaciones son hitos ineludibles en la historiografía sevillana y nuestro trabajo contribuirá a profundizar en el conocimiento de esta imagen en los centenarios de José Gestoso (Sevilla, 1852-1917) y del pintor Joaquín Domínguez Bécquer (Sevilla, 1817-1879).

Los dibujos van insertos en el volumen VII de sus Documentos varios, ordenado en agosto de 1893, formando un apartado o expediente titulado "Giralda y catedral, zapatos y dibujos de la Virgen de los Reyes". Éste recoge materiales y notas del desplome del pilar en 1888 publicados en la Ilustración Española e Iberoamericana, otros de la restauración de la Giralda y Giraldillo acompañadas de transcripciones de la documentación consultada en el archivo de la catedral y originales del cambio de la disposición de las cazuelas para las luminarias en diversas celebraciones. También dan informaciones de sus trabajos de conservación en este templo, caso del esquema de la disposición del retablo mayor, una relación de pinturas trasladadas al Palacio Arzobispal con motivo de las obras en 1888 y otros de la capilla Real. Estos últimos comprenden anotaciones de los relieves de las Virtudes teologales e inscripciones del basamento del altar de San Fernando, dos dibujos originales de José Gestoso del mecanismo interior y zapatos de la Virgen de los Reyes, otros de Joaquín Domínguez Bécquer de la Virgen y su Hijo con las coronas antiguas y una fotografía de la corona robada en 1873.

\section{JOSÉ GESTOSO Y PÉREZ (H. 1890-1893): DIBUJOS DE LAS ZAPATILLAS Y MECANISMO DEL MOVIMIENTO DE LA CABEZA DE LA VIRGEN DE LOS REYES}

Ambos dibujos a tinta están realizados con un trazo preciso, sin apenas levantar la mano del papel, partiendo de un sumario contorno a lápiz y rotulados con la singular caligrafía inglesa de José Gestoso. Suponen el primer documento gráfico de las características materiales de las zapatillas medievales y del mecanismo del movimiento de la cabeza de la Virgen de los Reyes hasta el reportaje fotográfico de Rafael de Salas, que documentó el informe de José Hernández Díaz del expediente del Patronato canónico de esta imagen y sus estudios de 1947 y $1971^{1}$.

${ }^{1}$ HERNÁNDEZ DÍAZ, José: La Virgen de los Reyes, patrona de Sevilla y de la Archidiócesis. Estudio iconográfico. Sevilla, 1947, p. 25, figs. 10 y 11; y HERNÁNDEZ DÍAZ, 
Dibujado en una cuartilla de papel (150 x $148 \mathrm{~mm})$, el mecanismo del movimiento de la cabeza representa un vástago circular en posición horizontal con una cinta enrollada, desplegada desde el límite superior de la hoja, y una sencilla rueda dentada con su lengüeta de freno en la parte derecha. Omite cualquier referencia gráfica al lugar preciso donde está alojado o a sus características materiales y, en la parte inferior, una anotación expone su finalidad: "Mecanismo que tiene la efigie de la Virgen de los Reyes, que se venera en la Real Capilla de San Fernando en el interior del torso, el cual parece que sirvió para transmitir movimientos a la cabeza de la venerada imagen"2 (Figura 1).

Los zapatos medievales de la Virgen de los Reyes comprenden tres dibujos a tinta del "perfil del zapato en todo su tamaño $(25 \mathrm{~cm})$ " (250 x $98 \mathrm{~mm})$, de su talón $(55 \times 84 \mathrm{~mm})$ y del empeine o frente $(141$ x $56 \mathrm{~mm})$ realizados en un folio de papel con un título realzado: "Zapatos de la Virgen de los Reyes". En medio de éstos, un texto autógrafo de Gestoso explica cuándo y cómo los analizó el 28 de octubre de 1890, en el contexto de la finalización de las reparaciones y obras de conservación encargadas en abril de aquel año ${ }^{3}$. Esta anotación y el índice del volumen permiten fechar las tres figuras del calzado y, por extensión, la del mecanismo, entre finales de 1890 y mediados de $1893^{4}$ :

"El martes 28 de octubre de 1890 acompañado solamente por el capellán mayor Il. Servando Arbolí, a las 12 y $1 / 2$ de la mañana, entramos en la Capilla Real y subidos en el altar quitamos a la Virgen primero unos zapatos de raso blanco bordados de oro, que fueron del Sr. Cascallana, después unas medias de seda encarnadas con cuchillos también de oro y por último otras de hilo, blancas, apareciendo entonces los zapatos aquí dibujados, cuyo estado de conservación es inmutable. Véase la descripción que hago de ellos en mi Sevilla monumental y artística" $^{5}$ (Figura 2).

Con este testimonio reconstruyó, paso a paso, con una redacción notarial cómo descalzaron y retiraron dos pares de medias de las piernas de la Virgen y descubrieron sus zapatos medievales, y remite para sus características al segundo volumen de su Sevilla monumental donde redactó un amplio estudio de diez

José: Iconografía medieval de la Madre de Dios en el antiguo reino de Sevilla. Discurso académico leído en el acto de su recepción en la Academia de Bellas Artes de San Fernando el 13 de junio de 1971. Madrid, 1971, figs. 4 y 5.

${ }^{2}$ Catedral de Sevilla, Biblioteca Capitular y Colombina (B.C.C.), Fondo Gestoso, Papeles varios. T. VII, $\mathrm{n}^{\circ} 35$, p. 242r. Tamaño del papel: $218 \mathrm{~mm}$ alto.

${ }^{3}$ Para las obras de conservación: GÓMEZ DE TERREROS GUARDIOLA, Ma del Valle: "La capilla Real de los siglos XIX y XX", en JIMÉNEZ, Alfonso (coord.): La capilla Real. XIX edición del Aula Hernán Ruiz. Sevilla, 2012, pp. 101-112.

${ }^{4}$ B.C.C., Fondo Gestoso, Papeles varios. T. VII, el dibujo de la portada de este tomo está fechado en "febrero de 1896" y el índice original-manuscrito de contenidos el 12 de agosto de 1893, h. 2r.

${ }^{5}$ B.C.C., Fondo Gestoso, Papeles varios. T. VII, expediente n ${ }^{\circ} 35$, p. 243 r. 
páginas, reiteradamente consultado y citado por la historiografía posterior. Aquí expuso por vez primera la finalidad de dicho mecanismo y redactó con precisión arqueológica las características de los zapatos. Además recogió una descripción de la primitiva capilla Real, tabernáculo, imágenes y monumentos funerarios en 1345 conocida por un manuscrito de la biblioteca de Hernán Pérez de Guzmán, alguna noticia del siglo XVI y los sellos medievales que había visto en la obra de Alonso Muñiz para argumentar que originariamente la Virgen llevaba al Niño en su costado izquierdo y lamentarse de las transformaciones realizadas tanto en el mobiliario medieval como en la forma de vestirla y la pérdida de la corona robada en $1873^{6}$. En aras de exponer los resultados de sus investigaciones omitió la mayoría de las fuentes manuscritas e impresas de los siglos XVI al XVIII restándoles importancia y remitiendo en nota a la lectura de su libro Curiosidades antiguas sevillanas, donde reeditó otro trabajo dado a conocer en el periódico El Orden en abril de $1883^{7}$. Este aparente desdén respecto a las fuentes modernas obedeció a su deseo por dejar constancia arqueológica de las características de la imagen y su calzado medieval y, apremiado por la edición de su Sevilla monumental, emitió solo su "juicio lealmente" y estableció los resultados de esta visita después de las limitaciones impuestas siete años antes ${ }^{8}$.

La trascendencia de estos dibujos inéditos, representados prácticamente a escala real, propician una reflexión historiográfica relativa a las características de la propia Virgen de los Reyes, a las fuentes consultadas y a la labor desarrollada por José Gestoso en la redacción y edición de su Sevilla monumental, en el centenario de su óbito. La reiterada lectura de este libro hizo pensar a algunos historiadores, que no consultaron sus Curiosidades, en un cierto menosprecio por las fuentes manuscritas e impresas de la capilla Real cuando, en realidad, aunque las omitió, las valoró junto al análisis artístico que le permitió constatar su veracidad.

El proyecto editorial Sevilla monumental y artística fue un encargo del Ayuntamiento de Sevilla, aprobado en su sesión celebrada el día 12 de febrero de 1883, su redacción le ocupó prácticamente nueve años y los tres volúmenes se publicaron en 1889, 1890 y 1892 respectivamente ${ }^{9}$. La magnitud del encargo y su amplia

${ }^{6}$ GESTOSO Y PÉREZ, José: Sevilla monumental y artística. Historia y descripción de todos los edificios notables, religiosos y civiles, que existen actualmente en esta ciudad y noticia de las preciosidades artísticas y arqueológicas. T. II. Sevilla, 1890, pp. 324-334.

7 GESTOSO Y PÉREZ, J.: Sevilla monumental... T. II, op. cit., pp. 324: “[...] acerca de la cual corren las más peregrinas tradiciones, y acerca de las cuales hacemos caso omiso, concretándonos solo a emitir nuestro juicio lealmente, según lo hicimos en otra ocasión. [...] Curiosidades antiguas sevillanas, tomo I, página 125 y siguientes".

8 GESTOSO Y PÉREZ, José: "Esculturas antiguas sevillanas", El Orden, abril de 1883, recorte conservado en B.C.C., Fondo Gestoso, Papeles varios. T. II, pp. 276-277.

9 RODRÍGUEZ JURADO, Adolfo: Homenaje rendido a la memoria de... José Gestoso y Pérez: discurso necrológico... el día 10 de diciembre de 1918... Sevilla, 1918, p. 36. 
capacidad intelectual le permitieron compatibilizar esta obra con la edición de sus libros Guía artística de Sevilla de 1884 o su Noticia histórico-descriptiva del antiguo pendón de la ciudad de Sevilla de $1885^{10}$, con sus colaboraciones de arte sevillano publicadas en varios periódicos y desarrollar sus múltiples actividades profesionales como archivero, académico de las sevillanas de Buenas Letras y Santa Isabel de Hungría, vocal-secretario de la Junta de Obras de la catedral de Sevilla y, entre otras de conservación en el mismo templo ${ }^{11}$. Su copiosa actividad intelectual, documental y editorial le hizo incorporar directamente en Sevilla monumental numerosos párrafos de textos dados a conocer en los periódicos El Orden, El Universal, La Andalucía Moderna, La Razón y la Ilustración artística o, incluso, reeditarlos en sus Curiosidades antiguas sevillanas. Serie arqueológica (1885), omitiendo habitualmente sus referencias ${ }^{12}$.

Sin embargo, las diez páginas dedicadas a la Virgen de los Reyes en Sevilla monumental tienen cambios respecto a sus publicaciones anteriores de $1883 \mathrm{y}$ 1885 y a otras partes de la misma obra, pues omitió las referencias relativas a los orígenes, descripciones y noticias recogidas por las fuentes de época moderna y redactó en su lugar ocho párrafos con las características de esta imagen, de las articulaciones de sus brazos y piernas, del mecanismo de movimiento de la cabeza y de sus zapatos ${ }^{13}$. Este novedoso discurso histórico descriptivo debió redactarlo inmediatamente después de su visita del 28 de octubre de 1890, cuando el segundo volumen de este libro estaría en un proceso editorial muy avanzado en la tipografía El Conservador de la calle Amor de Dios; la edición tiene fecha de 1890 y aquel otoño tendría corregidas las galeradas de las segundas o, incluso, terceras pruebas. La incorporación del nuevo texto no sería una tarea sencilla porque, a finales del siglo XIX, los procesos editoriales dilataban durante meses los laboriosos trabajos de imprenta; era necesario componer las cajas con las líneas de texto al pie de los chilabetes y recomponerlas después de las correcciones de las

${ }^{10}$ GESTOSO Y PÉREZ, José: Guía artística de Sevilla. Historia y descripción de sus principales monumentos religiosos y civiles y noticia de las preciosidades artístico-arqueológicas que en ellos se conservan de arquitectura, escultura, pintura, grabado, orfebrería, cerámica, etc. Sevilla, 1884, pp. 198; y GESTOSO Y PÉREZ, José: Noticia histórico-descriptiva del antiguo pendón de la ciudad de Sevilla. Sevilla, 1885, p. 50.

${ }^{11}$ B.C.C., Fondo Gestoso, Papeles varios. T. VII, n 35 , p. 244: Cuadros trasladados al Palacio Arzobispal en 1888 con motivo de las obras del templo catedral. GESTOSO Y PÉREZ, José: Una requisa de cuadros en la Catedral de Sevilla. Sevilla, 1909.

12 GESTOSO Y PÉREZ, José: Curiosidades antiguas sevillanas: estudios arqueológicos. Sevilla, 1885. El segundo volumen lo publicó con el título: Curiosidades antiguas sevillanas. Serie segunda. Sevilla, 1910.

${ }^{13}$ GESTOSO Y PÉREZ, José: Sevilla monumental... T. II, op. cit., pp. 324-328. En p. 324 , los zapatos "[...] que hemos tenido ocasión de examinar con mayor detenimiento. [...] no creemos que se nos motejará de minuciosos si los describimos detalladamente en gracia de la rareza, como ejemplares de calzado del siglo XIII”. 
galeradas en cada una de las sucesivas pruebas hasta la impresión final y la encuadernación. Ante esta circunstancia José Gestoso debió eliminar varios párrafos de la redacción original relativos a su procedencia y fuentes literarias, y acopló el nuevo al espacio de aquellos en el cuadernillo correspondiente de las galeradas ya corregidas ${ }^{14}$. La sincronía cronológica entre su visita y la edición del tomo ralentizaría la impresión final que se concluiría en 1891 sin efectuar cambios en la plancha de la portada tipográfica. Una decisión similar adoptaría, por ejemplo, en el transcurso del proceso editorial de su Historia de los barros vidriados sevillanos donde existen disonancias en las fechas de las dos portadas impresas ${ }^{15}$.

Los artículos de la Virgen de los Reyes y de la Virgen de la Cinta publicados en el periódico El Orden entre octubre de 1883 y enero del año siguiente bajo el titular Esculturas antiguas sevillanas constituyen, sin cambios significativos, el capítulo de igual denominación de sus Curiosidades antiguas sevillanas: estudios arqueológicos editado en 1885, como evidencian las correcciones y notas manuscritas de sus recortes de prensa conservados en la Biblioteca Colombina ${ }^{16}$. En estas publicaciones realizó una revisión de las obras manuscritas e impresas de las historias de la capilla Real escritas "con ligerísimas variantes" por Pablo Espinosa de los Monteros, Juan de Vilafañe, Juan de Pineda, Antonio de Quintanadueñas, Diego Ortiz de Zúñiga, Alonso Sánchez Gordillo, Antonio de Solís y Juan Bernal, José Maldonado de Saavedra, Juan de Lucas Cortés y Esteban de Garibay entre otros, cuyas citas y referencias habitualmente silenció la historiografía del siglo XX. La omisión de éstas en su Sevilla monumental o, mejor dicho, su eliminación en aras de manifestar los caracteres de la Virgen de los Reyes ha distorsionado el mérito que les confería. Además estas exclusiones propiciaron, a veces, interpretaciones erróneas del mecanismo del movimiento de su cabeza al deducir cierta relación o conexión mecánica entre este aparato y las articulaciones de sus miembros en aras de ver una "imagen viviente", con cierta movilidad semejante a algún autómata medieval. Estas interpretaciones no tienen en cuenta la absoluta necesidad de otro mecanismo para conseguir cierto desplazamiento autónomo porque siempre es necesaria la intervención directa de, al menos, dos

${ }^{14}$ GESTOSO Y PÉREZ, José: Sevilla monumental... T. II, op. cit., está formado por 77 cuadernillos de 4 hojas dobladas, numerados correlativamente. Las novedades historiográficas de la Virgen de los Reyes están impresas en el cuadernillo 41 (pp. 321-328) y ocupan las páginas 324-328 con una extensión equiparable a las que dedica en las Curiosidades..., pp. 125-134.

${ }^{15}$ GESTOSO Y PÉREZ, José: Historia de los barros vidriados sevillanos desde sus orígenes hasta nuestros días. Sevilla, 1904. La reedición del Ayuntamiento de Sevilla en 1995 incluye una "Presentación" de Alfonso PLEGUEZUELO (pp. I-XXIII) capital para conocer las vicisitudes de esta obra y personalidad de su autor.

${ }^{16}$ B.C.C., Fondo Gestoso, Papeles varios. T. II, pp. 275r-277r y 255. GESTOSO Y PÉREZ, J.: Curiosidades antiguas sevillanas..., op. cit., pp. 125-146. 
personas para realizar cualquier cambio en la disposición de esta imagen. Una revisión de estas fuentes y de los estudios posteriores permiten, hoy en día, valorar equitativamente las palabras con las que José Gestoso describió la capacidad de esta escultura para cambiarle de postura hasta conseguir mediante el movimiento de su cabeza y de los brazos variaciones expresivas, y el carácter de su extraordinario calzado medieval después de la restauración de Francisco Arquillo Torres en $1980^{17} \mathrm{y}$ de los trabajos de conservación del IAPH en $1998^{18}$. En esta última, que seguí directamente como conservadora de Bienes Muebles de la Catedral de Sevilla, constaté el resto de un vástago de hierro en la cadera izquierda que constituye el testimonio veraz de la disposición originaria de la Virgen de los Reyes con su Hijo en el regazo izquierdo ${ }^{19}$.

La Virgen de los Reyes es una talla completa en madera de tamaño natural (176 cm alto), concebida y realizada para vestir con las mejores galas y ser venerada con apariencia de veraz Soberana celestial. Su devoción está estrechamente vinculada a la personalidad del rey Fernando III, el santo, y sus primeras referencias literarias la relacionan con un suceso extraordinario narrado en la Cántiga CCICII. Una descripción de mediados del siglo XIV menciona expresamente que "semeja que está viva en carne, con su Fijo en el brazo" y "es fecha en torno, y la levantan y la asientan quando quieren para vestir á ella y al su Fijo: sus paños de carmesí, mantos, pelotes, é sayas" ${ }^{20}$. Este texto, conocido a partir de una narración de 1345 copiada por Hernán Pérez de Guzmán († h. 1460) y publicada por Diego Ortiz de Zúñiga (Sevilla, 1636-1680), fue leída por todos los historiadores sevillanos que escribieron sobre los orígenes, tradiciones e historia de esta imagen y permitieron a José Gestoso explicar en sus primeras publicaciones cómo podía cambiar la posición y altura de los brazos, colocarla en posición sedente o de pie. En 1883 únicamente pudo ver la cabeza y las manos con el mecanismo de las muñecas de la Virgen pero éstas le confirmaron las palabras que Pablo Espinosa de

${ }^{17}$ HERNÁNDEZ DÍAZ, José: La virgen de los Reyes..., op. cit., pp. 26-27, fig. 11. El análisis técnico, estado de conservación y tratamiento realizado por Francisco Arquillo Torres, constituyeron parte de la tesis doctoral de Joaquín Arquillo Torres: Aspectos socio-religiosos en la conservación de las representaciones escultóricas marianas. Influencia en tres imágenes medievales representativas. Facultad de Bellas Artes, Universidad de Sevilla, enero de 1989. http://fondosdigitales.us.es/tesis/tesis/240/aspectos-socio-religiosos-enla-conse/ (Consultado el 1-12-2016).

18 GONZÁlEZ LÓPEZ, Ma José: "Virgen de los Reyes", PH Boletín del Instituto Andaluz del Patrimonio Histórico, 7/n.27, 1999, p. 62. En 2015 Francisco Arquillo realizó un nuevo tratamiento de conservación.

19 LAGUNA PAÚL, Teresa: "Virgen de los Reyes", en BANGO, Isidoro (coord.): Las maravillas de la España medieval. Arte sagrado y monarquía sacra. T. I. Madrid, 2001, p. 435.

${ }^{20}$ ORTIZ DE ZÚÑIGA, Diego: Anales eclesiásticos y seculares de la Muy Noble y Muy Leal Ciudad de Sevilla. T. II. Madrid, 1795, pp. 143-145. 
los Monteros (1635) y el capellán de la Real Capilla Alonso Muñiz (1686) escribieron con relación a su excepcional melena de largos cabellos de hilos dorados, fijados con puntas a cabeza, y como "todo está perfectamente articulado con el mismo mecanismo de que se sirven los pintores en sus maniquíes y los autores que dejamos mencionados no se equivocaron al decir que es susceptible de todos los movimientos del cuerpo humano"21. Con las mismas palabras se refirió a las articulaciones de la imagen en su Sevilla monumental sin mencionar la validez de las fuentes y, por tanto, restándoles importancia ante la historiografía posterior. Estas articulaciones, "coyunturas" o "goznes" de las fuentes del siglo XVII, son unos pasadores de madera que permiten el engranaje del brazo en el hombro, del codo y de la muñeca, también flexionar las rodillas y en la cadera adoptar posición sedente o erguida, como muestra la documentación gráfica y fotográfica de la restauración de $1980^{22}$. Mecánicamente sus antecedentes más remotos pueden encontrarse en esculturas egipcias y romanas de pequeño formato -muñecas- y en otras posteriores con articulaciones en las muñecas y brazos que facilitan el vestirlas y su torso está anatomizado como otras esculturas del siglo XIII ${ }^{23}$.

El mecanismo y dibujo conservados recuerdan las características del dispositivo trazado por Villard de Honnecourt en su Cuaderno para explicar cómo un diácono durante la lectura del evangelio movía la cabeza de un águila, colocada en un atril. El artefacto de la rueda dentada, con su correa y tablilla de freno son iguales aunque difieren en cuanto a su colocación y, además, el del águila dispone de un asidero para accionarlo ${ }^{24}$. El de la Virgen de los Reyes es de madera, no de hierro como señala Gestoso, está alojado en el interior de la espalda de la figura y protegido con una tapa o portezuela lígnea que necesariamente debe permanecer abierta para cualquier manipulación, después de levantar o apartar las diferentes camisas que viste la imagen ${ }^{25}$. En su Sevilla monumental señaló las ropas que cubrían por completo el cuerpo de la Virgen y cómo este mecanismo transmitía originariamente "a la cabeza otros movimientos" y se encontraba inutilizado ${ }^{26}$.

${ }^{21}$ GESTOSO Y PÉREZ, J.: "Esculturas antiguas...”, op. cit., p. 276; GESTOSO Y PÉREZ, J.: Curiosidades antiguas sevillanas..., op. cit., pp. 127, 129 y 132; y GESTOSO Y PÉREZ, J.: Sevilla monumental... T. II, op. cit., p. 325.

22 ARQUILLO TORRES, J.: Aspectos socio-religiosos en la conservación..., op. cit., pp. 63-64 y 70-74.

${ }^{23}$ LAGUNA PAÚL, T.: "Virgen de los Reyes", op. cit., p. 435; y LAGUNA PAÚL, Teresa: "Devociones reales e imagen pública en Sevilla", Anales de Historia del Arte, 23/ II, pp. 137-140.

${ }^{24}$ LAGUNA PAÚL, T.: "Virgen de los Reyes", op. cit., p. 435.

${ }^{25}$ Fotografía del mecanismo interior y portezuela en HERNÁNDEZ DÍAZ, J.: $L a$ Virgen de los Reyes..., op. cit., fig. 11; y ARQUILLO TORRES, J.: Aspectos socio-religiosos en la conservación..., op. cit., pp. 422-423, fig. 13.

${ }^{26}$ GESTOSO Y PÉREZ, J.: Sevilla Monumental... T. II, op. cit., p. 325. 
Estos cambios o desplazamientos de la posición de la cabeza, las distintas actitudes o gestos expresivos de los brazos y el vestuario de esta imagen causarían gran impacto entre los fieles y acrecentaron la devoción medieval a esta imagen. La Virgen de los Reyes es la escultura medieval mejor conservada de las denominadas "imágenes vivas" o, mejor dicho, que parecen vivas porque su morfología estructural y ropas permiten cambios puntuales en su aspecto, potencian su comunicación con los fieles y la comprensión de lo sagrado.

En el contexto escenográfico de la capilla de los Reyes y de la retórica visual organizada por Alfonso X para el espacio funerario de sus progenitores, la Virgen dentro de su tabernáculo veló el eterno descanso del rey santo ataviada con las mismas ropas ceremoniales de los soberanos y reinas castellanas del siglo XIII, descritas en la narración de 1345 y única fuente recogida por él en Sevilla monumental. Los historiadores sevillanos del siglo XVII y XVIII aportaron noticias e informaciones posteriores relativas al vestuario de la Virgen y, entre éstos, el capellán real Alonso Muñiz dio las referencias más precisas del calzado medieval redescubierto por Servando Arbolí y José Gestoso bajo dos pares de medias y unas zapatillas de raso bordadas en oro, regaladas por el obispo don Juan Nepomuceno Cascallana y Ordóñez (Sevilla, 1785-Málaga, 1868) que sustituirían a otras de época moderna cuando adaptaron las vestiduras de esta imagen a la estética imperante de aquellos siglos ${ }^{27}$. Estas zapatillas y un inventario de 1500 ilustran sobre el carácter del ajuar medieval de la Virgen con sus ropas esculturadas, su calzado de cordobán y su espectacular corona de oro de la reina Beatriz de Suabia y, que según la tradición, fue regalo de Fernando III $^{28}$.

Gestoso en los tres dibujos arqueológicos del calzado hace, prácticamente, una ilustración del pormenorizado análisis incluido en dos páginas de Sevilla monumental y, además, manifiesta la preparación intelectual y sus preferencias estéticas por la Edad Media ${ }^{29}$. Los zapatos adaptados como un guante al pie de la escultura miden $25 \mathrm{~cm}$, la pala está decorada con una flor de lis de color rojo cobrizo rodeada por tres estrellas de ocho puntas a cada lado, en el puente la palabra "AMOR" inserta con letras lombardas y en el talón una cruz flanqueada por cuatro palomas y dos estrellas. Este calzado confeccionado con dos piezas

${ }^{27}$ MUÑIZ, Alonso: Insinuazión apologética al Rey Nuestro Señor D. Carlos $2^{\circ}$, que Dios guarde, por su Santa y Real Capilla de la ciudad de Sevilla [...] (20-7-1775). B.C.C., 58-4-15, pp. 75-76; y RODRÍGUEZ LÓPEZ, Pedro: Episcopologio asturicense. T. IV. Astorga, 1910, pp. 257-264. Estos zapatos serían parecidos a los actuales de raso blanco bordado en oro confeccionados en 1939 por el taller Facundo.

${ }^{28}$ LAGUNA PAÚL, Teresa: "Imperio y corona de Castilla: la visita a la capilla de los Reyes en Sevilla en 1500", en COSMEN, M ${ }^{\mathrm{a}}$ C.; HERRAEZ, M ${ }^{\mathrm{a}}$ V.; y PELLÓN, M ${ }^{\mathrm{a}}$ (coords.): El intercambio artístico entre los reinos hispanos y las cortes europeas en la Baja Edad Media. León, 2009, pp. 224-231 y 233-235.

${ }^{29}$ GESTOSO Y PÉREZ, J.: Sevilla monumental... T. II, op. cit., pp. 326-328. 
de cordobán blanco, casi una piel de badana, su decoración en color rojo cobrizo está cosida con un punto invisible por el reverso de la pieza y toda la superficie presenta numerosos círculos pequeños grabados. José Gestoso consideró estos zapatos obra mudéjar e interpretó las flores de lis como un recuerdo de su procedencia francesa y de las relaciones familiares de Luis IX Valois con Fernando III, al igual que todos los historiadores desde el siglo $\mathrm{XVI}^{30}$ (Figura 2).

La dificultad para analizar este calzado con otros del mismo período, su decoración flordelisada con la palabra "AMOR" y las ropas que vestía la imagen en época medieval hicieron pensar que todo este ajuar perteneciera en origen a la reina doña Beatriz cuya corona llevó hasta $1873^{31}$. No obstante los paralelos con algunos zapatos litúrgicos, confeccionados en guadamecíes con incrustaciones de cueros de distinto color, parecen corroborar que este calzado está directamente ligado a la factura de la escultura, a su carácter cultual y, en definitiva, al universo de la espiritualidad que conduce al fervor mariano porque sus características complementan la iconografía de la Virgen de los Reyes. La flor de lis es un atributo mariano que alude también a la Trinidad, las estrellas de ocho puntas o flores del mismo número de pétalos suelen adornar el velo y los ropajes de numerosas vírgenes desde la plena Edad Media asociándose en la iconografía cristiana a la Estrella de la Mañana, a la Madre de Dios. En la propagación del culto mariano en la Edad Media, San Bernardo fue quien desarrolló un sistema místico por el que los cristianos son transformados por el Amor, manifiesto igualmente en las obras de Gonzalo de Berceo, Gautier de Coincy y otras inspiradoras de las Cantigas de Alfonso X. Complemento indispensable del culto de latría de esta imagen en el altar mayor de la catedral fue un baldaquino, templete o tabernáculo cuyas características originarias son desconocidas, ya que todas las fuentes posteriores mencionan un tabernáculo adscrito a las empresas de Alfonso X y recientemente estudiado ${ }^{32}$.

\section{DIBUJOS DE LAS CORONAS DE LA VIRGEN DE LOS REYES}

Al final del mismo expediente con informaciones de la catedral de Sevilla ordenadas en agosto de 1893, José Gestoso incluyó una fotografía de la "corona de

${ }^{30}$ GESTOSO Y PÉREZ, J.: Sevilla monumental... T. II, op. cit., pp. 326-328; HERNÁNDEZ DÍAZ, J.: La Virgen de los Reyes..., op. cit., pp. 26-29, fig. 11; y LAGUNA PAÚL, T.: "Devociones reales...", op. cit., pp. 137-140 y fig. 4.

31 Para el ajuar medieval, LAGUNA PAÚL, T.: "Imperio y corona...”, op. cit., pp. 224-235.

${ }^{32}$ LAGUNA PAÚL, T.: "Devociones reales...”, op. cit., pp. 139-140 y fig. 4; y LAGUNA PAÚL, Teresa: "Mobiliario medieval de la capilla de los Reyes de la catedral de Sevilla. Aportaciones a los 'ornamenta ecclesiase' en su etapa fundacional”, Laboratorio de Arte, 25, 2013, pp. 53-77. 
la Virgen de los Reyes que fue robada la noche del 30 de abril de 1873, con el joyel o pectoral"33, cuando él tenía veintiún años, y dos dibujos del pintor Joaquín Domínguez Bécquer (Sevilla, 1817-1893). Estos dibujos de las cabezas de la Virgen de los Reyes $(169$ x $155 \mathrm{~mm})$ y su Niño $(134$ x $136 \mathrm{~mm})$ con sus coronas antiguas, realizados a lápiz en dos fragmentos de papel agarbanzado, están recortados y encolados en un folio cuyo título los identifica como originales de este artista, pero carece de otras anotaciones relativas a su procedencia o fecha de realización ${ }^{34}$. Desconocemos todavía cómo llegaría a su colección y si fue un regalo del mismo artista, de su familia o, incluso, de los duques de Montpensier dadas sus estrechas relaciones de este pintor y profesor de dibujo de sus hijos (Figura 3).

La fotografía de la corona es una copia muy deteriorada y recortada de la que fotografió y editó Jean Laurent Minier en su campaña de 1872. Robada del camarín de la Virgen la noche del 31 de marzo de 1873, la "corona de las águilas" del siglo XIII perteneció a la reina Beatriz de Suabia y posteriormente le incorporaron un joyel con un águila de los Austrias, constaba de diez y ocho piezas o placas articuladas, altas y bajas, con unos característicos copetes que acogían águilas de oro cincelado rodeadas de zafiros, perlas y esmeraldas engastadas en cápsu$\operatorname{las}^{35}$. La fotografía de Laurent también ilustró a Eusebi Planas su litografía de los "Restos y recuerdos de Don Fernando el santo" inserta en la Historia General de España de Modesto Lafuente en 1877, obra capital de la historiografía decimonónica que tenía José Gestoso en su biblioteca. Esta corona medieval de la Virgen y la barroca de oro y esmaltes del Niño eran las únicas que tenían estas imágenes, siempre permanecieron sobre sus cabezas en el retablo-camarín de la capilla Real hasta la primavera de 1873 cuando el robo de la primera obligó a reemplazarla de forma inmediata por otra del orfebre José Lecaroz y en 1889 compraron una de plata para preservar la barroca del $\mathrm{Niño}^{36}$.

Los dibujos de Joaquín Domínguez Bécquer muestran con bastante precisión el alto canasto de esta corona gótica con su característico perfil y detalles, mientras en la barroca del Niño los trazos esbozan solo la diadema con sus imperiales. Estos rasgos podrían indicar un dibujo del natural, unos apuntes tomados

${ }^{33}$ B.C.C., Fondo Gestoso, Papeles varios. T. VII, expediente n ${ }^{\circ} 35$, p. 241r. La fotografía no fue rotulada por José Gestoso y tiene la fecha del robo confundida. El robo tuvo lugar la tarde o noche del 31 de marzo de 1873, Véase: LAGUNA PAÚL, Teresa: "El robo de la corona de las águilas y las coronas del siglo XIX de la Virgen de los Reyes", Laboratorio de Arte, 27, 2015, pp. 345-346.

34 B.C.C., Fondo Gestoso, Papeles varios. T. VII, expediente no 35 , p. 240r. La escritura difiere completamente de la de José Gestoso y de Joaquín Domínguez Bécquer según una carta de este pintor conservada en el Museo Nacional del Romanticismo (Inv. FD3679).

${ }^{35}$ LAGUNA PAÚL, T.: "El Imperio y la Corona...”, op. cit., pp. 225-237; y LAGUNA PAÚL, T.: "El robo de la corona...", op. cit., pp. 345-348.

${ }^{36}$ LAGUNA PAÚL, T.: "El robo de la corona...", op. cit., pp. 345-346. 
para realizar alguna de sus pinturas del interior de la catedral o reproducción de esta imagen o ciertos encargos de los duques de Montpensier como fueron, por ejemplo, el velatorio y funerales del infante don Felipe en la capilla Real de Sevilla de $1664^{37}$. La cercanía con los duques y la devoción de éstos a la Virgen de los Reyes podría haberle facilitado un acceso al camarín antes del indicado robo de 1873 , cuando este pintor y reputado dibujante tenía cincuenta y seis años, o bien recrearla posteriormente con ayuda de la fotografía de Laurent lo cual explicaría las diferencias gráfico descriptivas de ambas coronas en los dibujos.

Los cuatro dibujos del volumen VII no son los únicos de la Virgen de los Reyes conservados en esta colección. La dilatada vida profesional e investigadora de José Gestoso le llevó a formar una amplia biblioteca y archivo personal, que encuadernó atendiendo a criterios temáticos, a la secuencia cronológica de algunos acontecimientos y organización de su archivo-biblioteca. Así sus relaciones con el marqués de la Vega Inclán y el marqués de las Navas le llevaron a solicitar copias de algunos manuscritos de la historia de Sevilla conservados en la Real Biblioteca entre los que hay un inventario de esta capilla ${ }^{38}$. Su dedicación al patrimonio, su pertenencia a distintas academias, sus trabajos en el archivo del Alcázar y en el Municipal, entre otros, le convirtieron en protagonista o participante ineludible para cualquier consulta o reunión relacionada con el patrimonio y empresas artísticas de la ciudad de Sevilla, que le determinaron sintonías y discrepancias con algunos acuerdos o decisiones adoptadas.

Entre estas colaboraciones suyas destaca, por el tema que nos ocupa, el concurso convocado por el arzobispado para realizar las coronas de la Virgen de los Reyes y su Hijo con motivo de la coronación canónica de esta imagen en 1904. El curso de los acontecimientos y decisiones le hicieron discrepar enérgicamente en su conocida publicación Tres cartas a Don Servando Arbolí donde manifestó y recomendó cómo esta imagen debía recuperar su aspecto original representado en los sellos más antiguos, cambiar y adecuar sus ropas a otras de índole o inspiración gótica, diseñarle un paso nuevo tomando como modelo el tabernáculo medieval y realizar una corona neogótica acorde con su carácter artístico ${ }^{39}$.

El desarrollo del primer concurso de ideas convocado por el arzobispado hispalense para la realización de las nuevas coronas de la Virgen en 1904, las sucesivas reuniones a las que fueron convocados los miembros de la comisión y las noticias publicadas en la prensa local desde junio de 1904 alteraron las condiciones del

${ }^{37}$ Para estas obras véase LLEÓ CAÑAL, Vicente: La Sevilla de los Montpensier. Sevilla, 1997, p. 199; y LLEÓ CAÑAL, Vicente y VALDIVIESO GONZALEZ, Enrique: La pintura en Sevilla en la época de los Montpensier. Sevilla, 1979, p. 200. Para la biografía del pintor véase RUBIO JIMÉNEZ, Jesús y PIÑANES GARCIA-OLIAS, Manuel: Joaquín Domínguez Bécquer. El guardián del Real Alcázar de Sevilla. Sevilla, 2014, pp. 17-100.

${ }^{38}$ B.C.C., Fondo Gestoso, Tomos varios XVI, nº 21 y 22.

39 GESTOSO Y PÉREZ, José: Tres cartas a Don Servando Arbolí. Sevilla, 1904. 
pliego inicial del certamen y la evaluación de las propuestas presentadas desde parámetros distintos al primer fallo y su adjudicación del mes siguiente. Estas circunstancias le dejaron un agrio recuerdo y, en los últimos años de su vida, cuando reflexionó sobre esta y otras experiencias patrimoniales al ordenar sus últimas notas, recortes de prensa y fotografías escribió de su puño y letra unos comentarios muy personales que documentan y aportan luz a dicho concurso y encargo.

En estos últimos cuenta qué circunstancias rodearon la adjudicación definitiva de la corona de la Virgen de los Reyes al joyero Pedro Vives, los cambios acaecidos después del fallo inicial del concurso y encargo de una corona neogótica de oro, esmaltes, perlas y piedras preciosas al orfebre José Lecaroz en el mes de agosto de 1904, quien realizó un prototipo en latón para comprobar su proporción adecuada y otras inversiones iniciales derivadas de su encargo. Presiones externas conllevaron variaciones en la decisión inicial del arzobispado que originaron réplicas de José Gestoso y otros asesores artísticos de la comisión formada al efecto. En estos párrafos de encendida censura, de contumaz ironía y acritud, hizo valoraciones estéticas de algunos diseños presentados e incorporó uno de los seis proyectos aportados por José Lecaroz al certamen ${ }^{40}$.

El boceto neogótico fue un encargo de este orfebre al pintor y ceramista José Macías (El Madroño, 1879-Sevilla, 1963). Realizado al temple en papel agarbanzado, muestra uno de los entregados al certamen $(99 \times 168 \mathrm{~mm})^{41}$. Esta corona de perfil flordelisado bordeada de perlas, cuajada y decorada con piedras en cabujón y esmaltes con los escudos de Castilla y León tiene una vinculación con la maqueta de latón mencionada en sus últimas notas, cuyo documento gráfico permanece en la fototeca del Laboratorio de Arte. El boceto podría ser testimonio de una asesoría de José Gestoso en los proyectos neogóticos de José Lecaroz pero, a falta de nuevos datos, consideramos se lo proporcionó el mismo pintor que le hizo en 1913 el retrato conservado en la Biblioteca Capitular y Colombina ${ }^{42}$. Este boceto y la fotografía realizada por Antonio Sancho Corbacho y José María González Nandín abrirán nuevos capítulos en el estudio del ajuar de la Virgen de los Reyes del siglo XX (Figuras 4 y 5).

Fecha de recepción: 12 de febrero de 2017

Fecha de aceptación: 20 de febrero de 2017

${ }^{40}$ B.C.C., Fondo Gestoso, 79-3-11 (Olim 114-6bis-9): "De historia sevillana. Páginas de mi vida", Apéndice 10, pp. 122-209.

${ }^{41}$ B.C.C., Fondo Gestoso, 79-3-11: "De historia sevillana....", p. 200: "Copiada del original hecha por mi para el platero José Lecaroz. José Macías".

42 IAPH, Base de datos del Patrimonio mueble en Andalucía, código 95899: http:// www.iaph.es/patrimonio-mueble-andalucia/resumen.do;jsessionid=9540A69FE04DACB 41298F747909C8C84?id=95899\&_lang=en (Consultado 18-11-2016). 


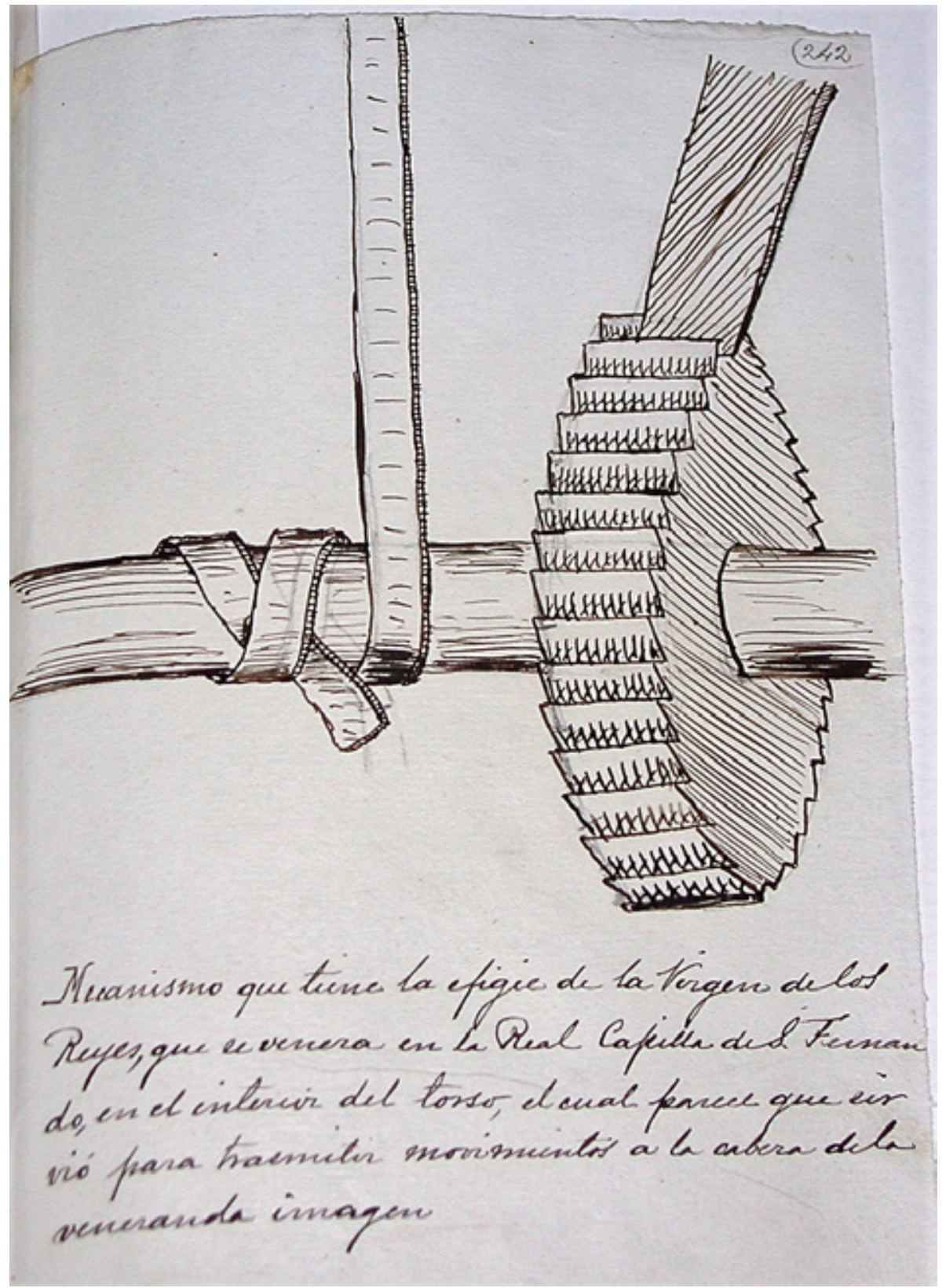

Figura 1. José Gestoso y Pérez, Dibujo del mecanismo del movimiento de la cabeza de la Virgen de los Reyes, 1890-1893. Catedral de Sevilla, B.C.C., Fondo Gestoso, Papeles varios. T. VII, h. 242r. 


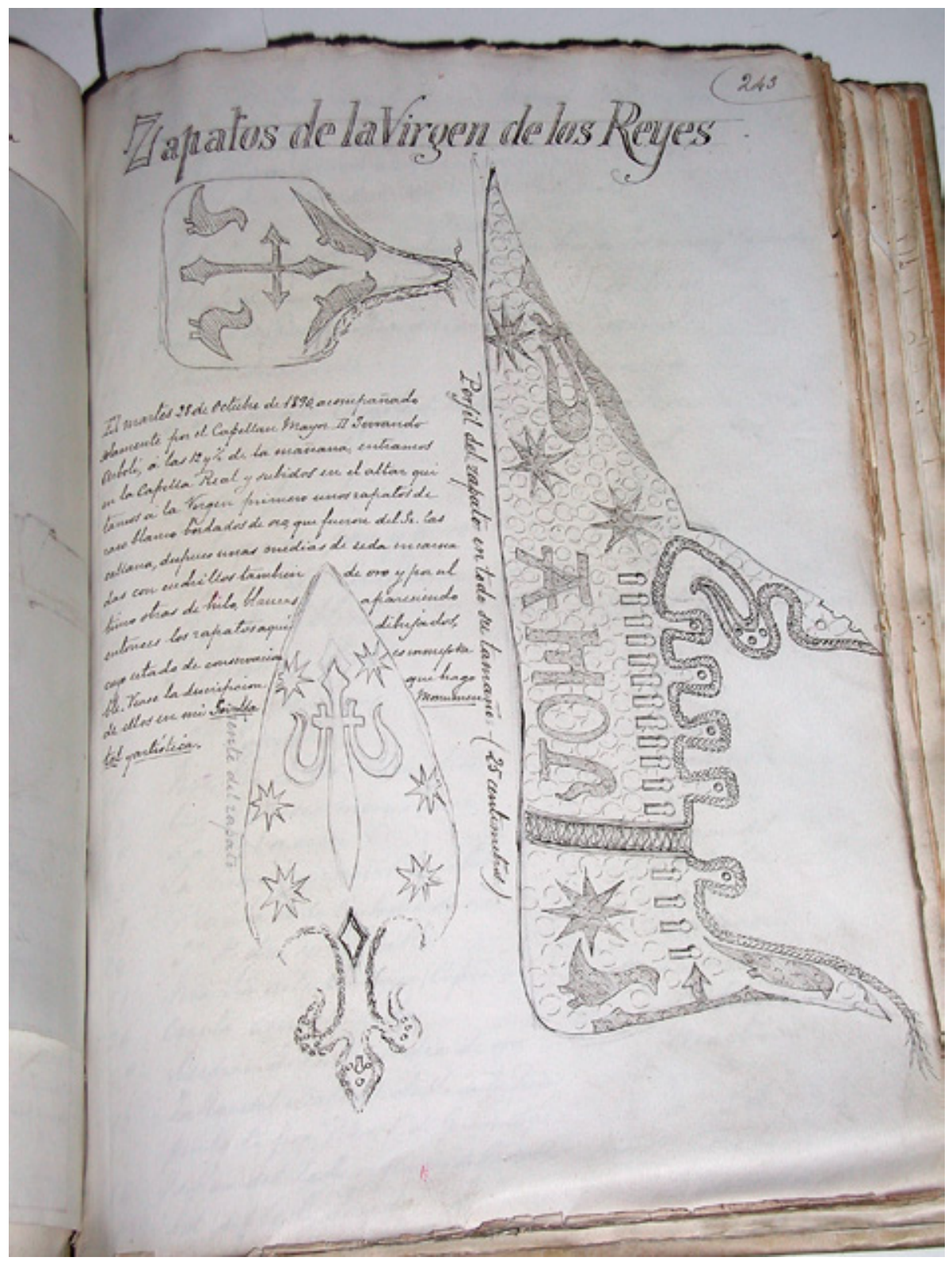

Figura 2. José Gestoso y Pérez, Dibujo de las zapatillas de la Virgen de los Reyes, 1890-1893. Catedral de Sevilla, B.C.C., Fondo Gestoso, Papeles varios. T. VII, h. 243r. 


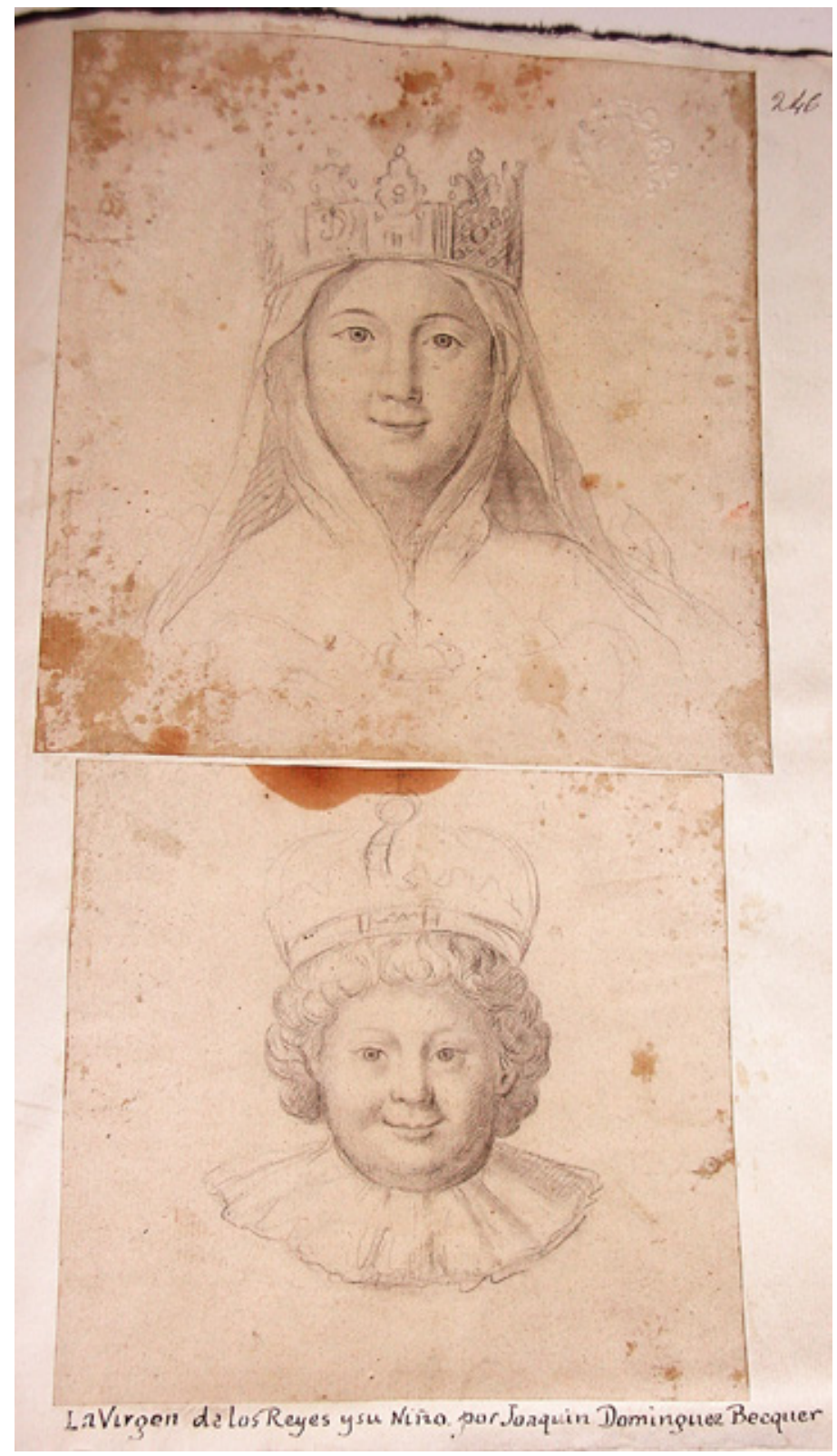

Figura 3. Joaquín Domínguez Bécquer, Dibujos de las cabezas de la Virgen de los Reyes y su Niño con sus coronas antiguas. Catedral de Sevilla, B.C.C., Fondo Gestoso, Papeles varios. T. VII, 246r. 


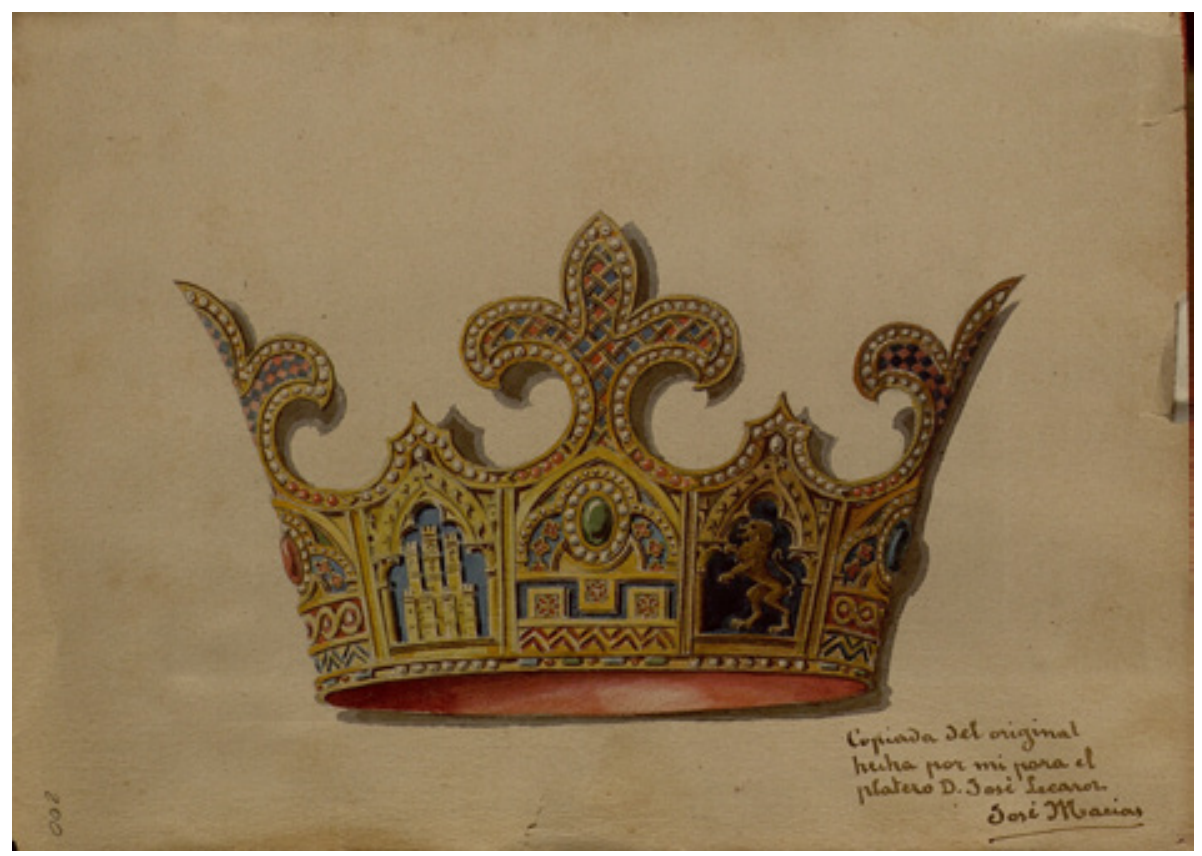

Figura 4. José Macías y Macías, Dibujo de un proyecto presentado por el orfebre José Lecaroz al concurso de las nuevas coronas de la Virgen de los Reyes y su Niño, 1904. (C) Catedral de Sevilla, B.C.C., Fondo Gestoso, 79-3-11, h. 200. 


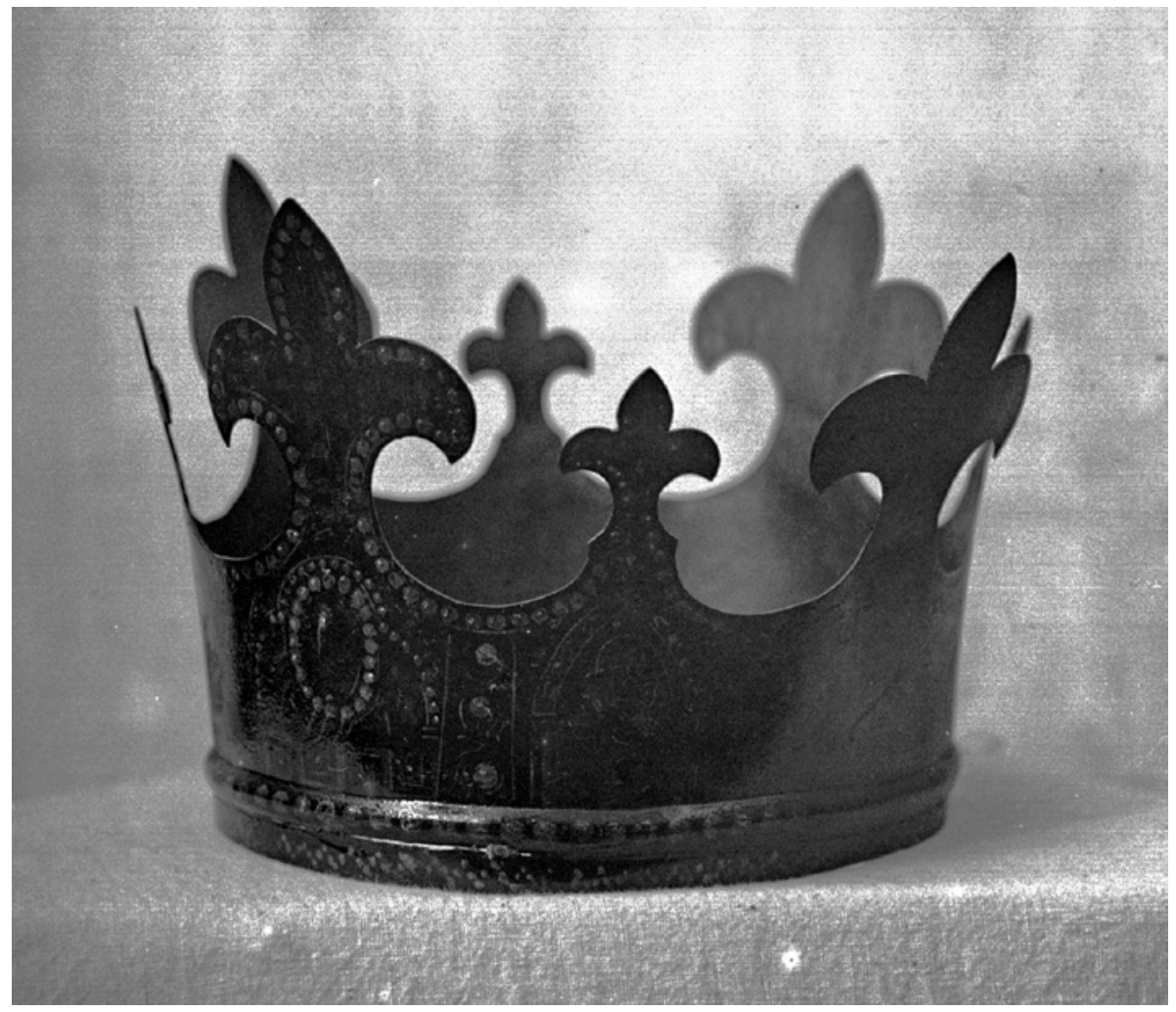

Figura 5. Maqueta de latón pintado de la corona de la Virgen de los Reyes adjudicada al orfebre José Lecaroz, 1904. Fotografía: Antonio Sancho Corbacho y José María Nandín y Paul (s.f.). (C) Universidad de Sevilla. Fototeca del Laboratorio de Arte. 